\title{
Drape mesh protection at the Savage River Mine, Tasmania
}

\author{
B.J. Hutchison Grange Resources (Tasmania) Pty Ltd, Australia \\ G.K. Macqueen Grange Resources (Tasmania) Pty Ltd, Australia
}

S.L. Dolting Grange Resources (Tasmania) Pty Ltd, Australia

A.T. Morrison Geobrugg Australia Pty Ltd, Australia

\begin{abstract}
In June and August of 2010 Grange Resources experienced two large wall failures at their Savage River Mine in Tasmania, Australia. These rockslides buried a significant portion of the magnetite ore scheduled to be mined in the following two years. To ensure long term ore supply, a major cutback was required to get back down onto the orebody. Several different approaches and mine plans were considered before deciding on a cast blast and drape mesh option to speed up the bench advance. Various mesh design schemes were assessed, before selecting a Geobrugg drape mesh system to cover the 60 to $80 \mathrm{~m}$ high, steeply dipping, haematite coated shear. The intent was to allow rapid mining bench advances during the cutback and rockslide removal process. By adopting this approach considerable time was saved by eliminating extensive pre-splitting, trim blast and rock support requirements associated with Grange's normal mining procedures.

Two large cast blasts were taken to remove rock material in front of the back scarp. The cast blasts were each $40 \mathrm{~m}$ in height and cast 30-35\% of the blasted rock off the face from in front of the haematite coated shear, which formed the back scarps of the two rock failures.

The drape mesh system was installed between April and October of 2011. The system was very successful in protecting personnel and equipment from rockfalls on the backscarp during the subsequent mining phase.

This paper describes the various processes associated with mine planning, cast blasting, drape mesh design, drape mesh tendering and selection, and installation; as well as the costs. The performance of the mesh in retaining potential and actual rockfalls is also described; along with issues associated with radar monitoring.
\end{abstract}

\section{$1 \quad$ Introduction}

Grange Resources mines and processes magnetite ore at its Savage River Mine located on the west coast of Tasmania in a temperate rainforest environment subjected to nearly $2,000 \mathrm{~mm}$ of rainfall annually. The mine has been in operation since the mid 1960s. Throughout its life, the open pit operation has experienced many large scale wall failures in its various open pits, due mainly to the highly sheared nature of the main host assemblage of rocks containing the ore.

North Pit, (Figure 1), has been mined since the mid 1980s in a series of cutbacks and has experienced many episodes of large scale wall failure comprising several different mechanisms; mainly toppling, circular and slump failures. These have occurred on the northern and western walls, where relatively weak and well sheared schistosic rocks prevail. The western wall has typically been cut at inter-ramp angles in the order of $35-37^{\circ}$, with one or two ramps of 25 to $36 \mathrm{~m}$ in width.

The spooned shape of the orebody has allowed (for economics) the main access route to come down through the southern 'handle' area and along the western wall; switch backing on that wall to stay away from numerous large scale slumping and circular wall failures experienced on the northern wall. Several multi-bench toppling failures have occurred on the western wall. They typically have taken several months 
to fully develop before collapsing and rilling down onto the main ramp. Due to the flatness of the western wall these major toppling events have created only minor disruptions to mining and have not led to loss of ore supply.

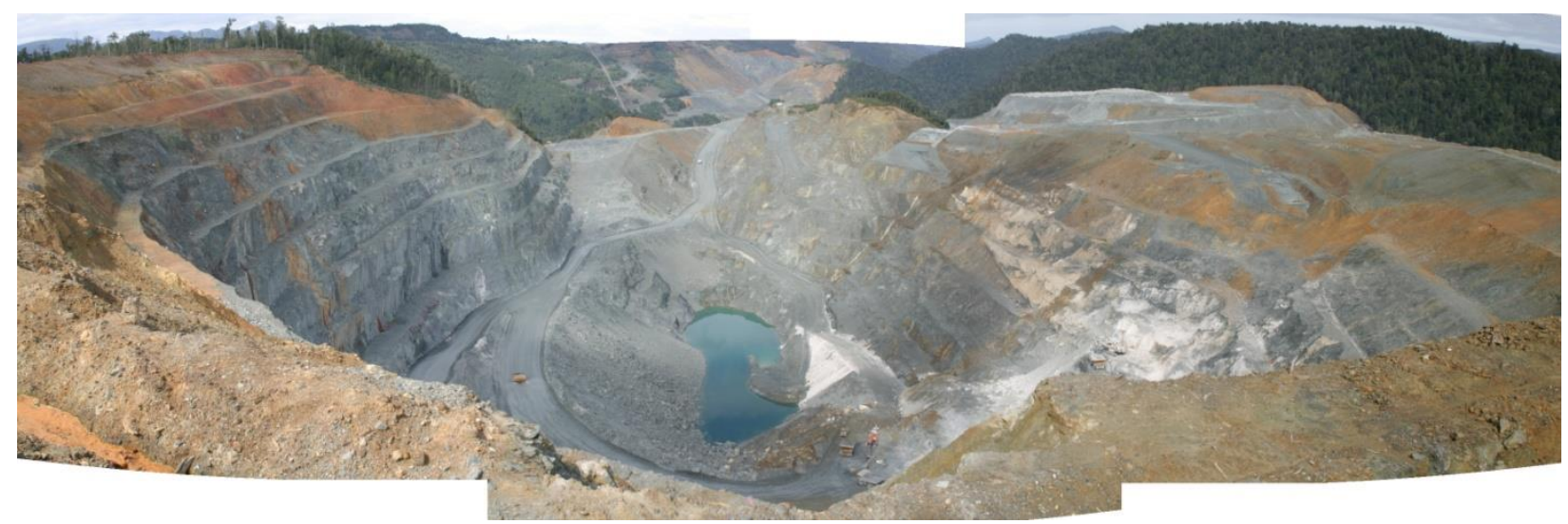

\section{Figure 1 Photograph of North Pit (looking south)}

The aforementioned large scale slump and circular failures of the northern wall have caused more significant delays to mining and in one case required ore supply to be completely diverted to another pit for almost one year. The weak nature of the schistose rock has however led to the failed rock mass breaking down to such an extent that mining from the toe of these slips has been possible, greatly assisting remediation efforts. Four of the five major wall failures have been effectively removed from the toe over a period of a few weeks and mining has continued.

Historically the eastern wall has been mined at an intermediate slope angle of $63^{\circ}$, being comprised mainly of $20 \mathrm{~m}$ high presplit faces, with $10 \mathrm{~m}$ wide berms (Figure 2). By 2010 this eastern wall had reached an overall height of $330 \mathrm{~m}$, due to the competency of the calcite-chlorite schist (amphibolite) in the mid-reaches of the wall.

Until 2010 the eastern wall had experienced no multi-bench failures, other than one $40 \mathrm{~m}$ high wedge failure in a completed section of the pit. Most stability issues involved small rockfalls and planar crest failures associated with $40-55^{\circ}$ westerly dipping joints, referred to locally as 'ski-jump' joints.

On 17 June 2010, a 400,000 t section of the eastern wall collapsed in the region of a small bullnose in the wall (Figures 2 and 3). This section of the wall had been exposed and had been stable for four years. The failure was structurally controlled by two joints; a ski-jump joint $\left(54^{\circ} / 270^{\circ}\right)$ and a northwesterly dipping joint $\left(46^{\circ} / 299^{\circ}\right)$; which formed a basal wedge surface (with a line of intersection dipping $43^{\circ} / 321^{\circ}$ ). The main backscarp was a $70-75^{\circ}$ westerly dipping haematite shear.

Following a major investigation, a second potential wall failure was identified to the south, where mining of the next cutback around the southern and eastern part of the pit was ongoing. The haematite shear had been mapped back into this area and it was noted that if a continuous ski-jump joint existed in this part of the wall, then a major planar failure might ensue; with the haematite shear forming a backscarp. Although a major continuous ski-jump joint had not been encountered prior to the 17 June 2010 failure, it was decided to continue cautiously mining this area in case one did emerge.

On 30 August 2010 a second failure comprising 200,000 tonne of rock occurred when a trim blast daylighted another ski-jump joint (Figure 4). The base of both slips daylighted in the pit wall well above the contact with the ore. 


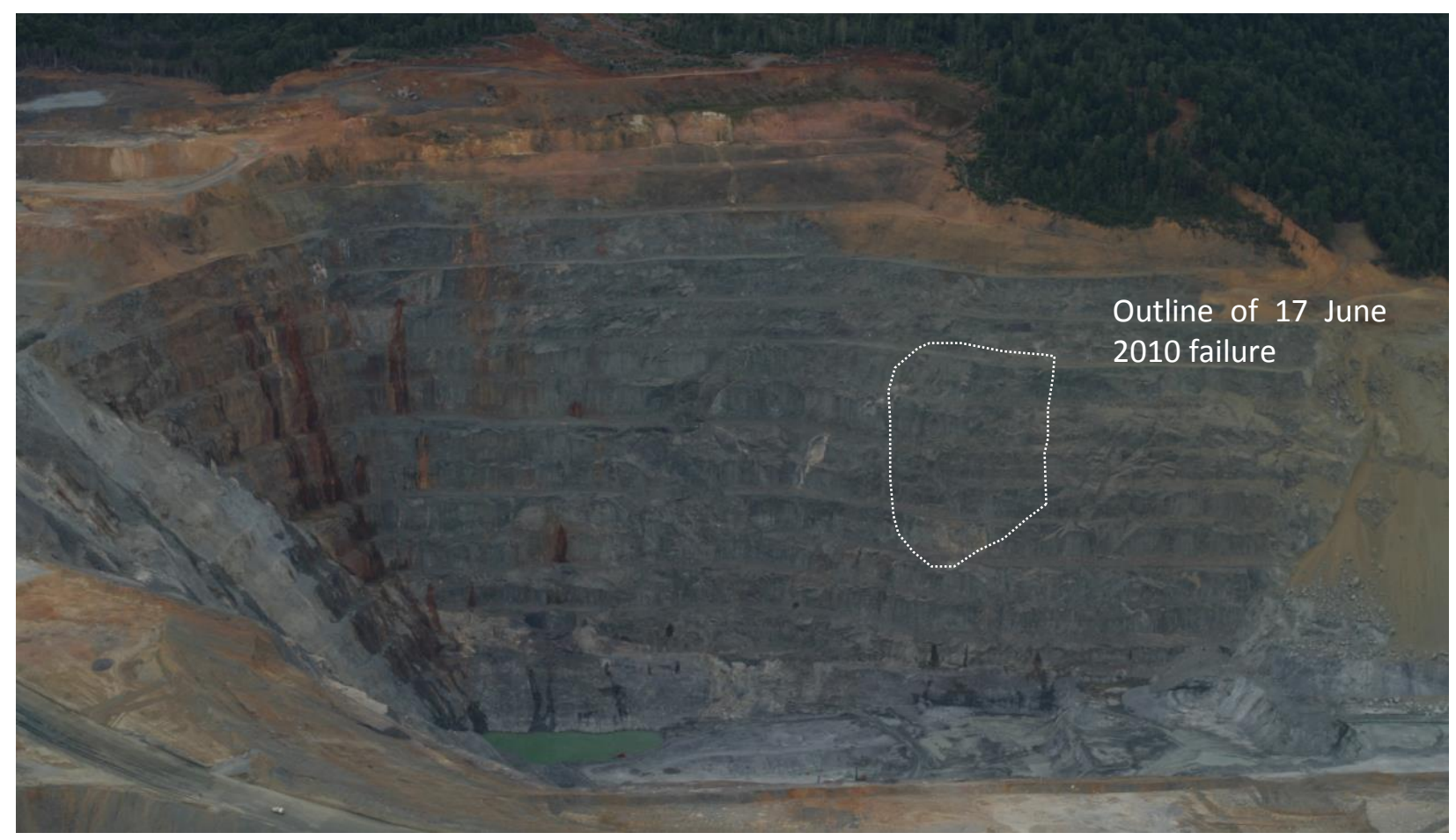

Figure 2 North Pit east wall

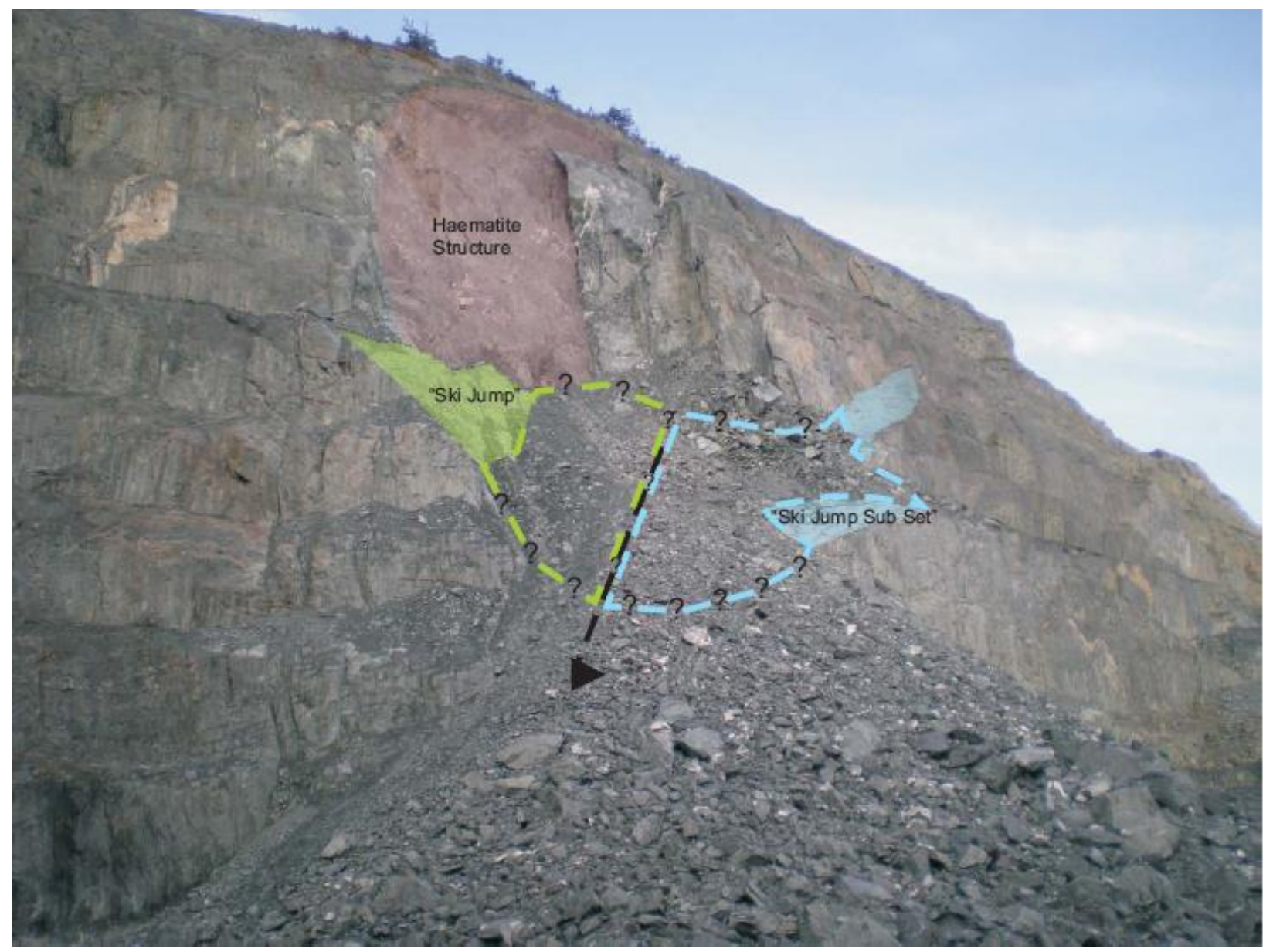

Figure 317 June 2010 failure 


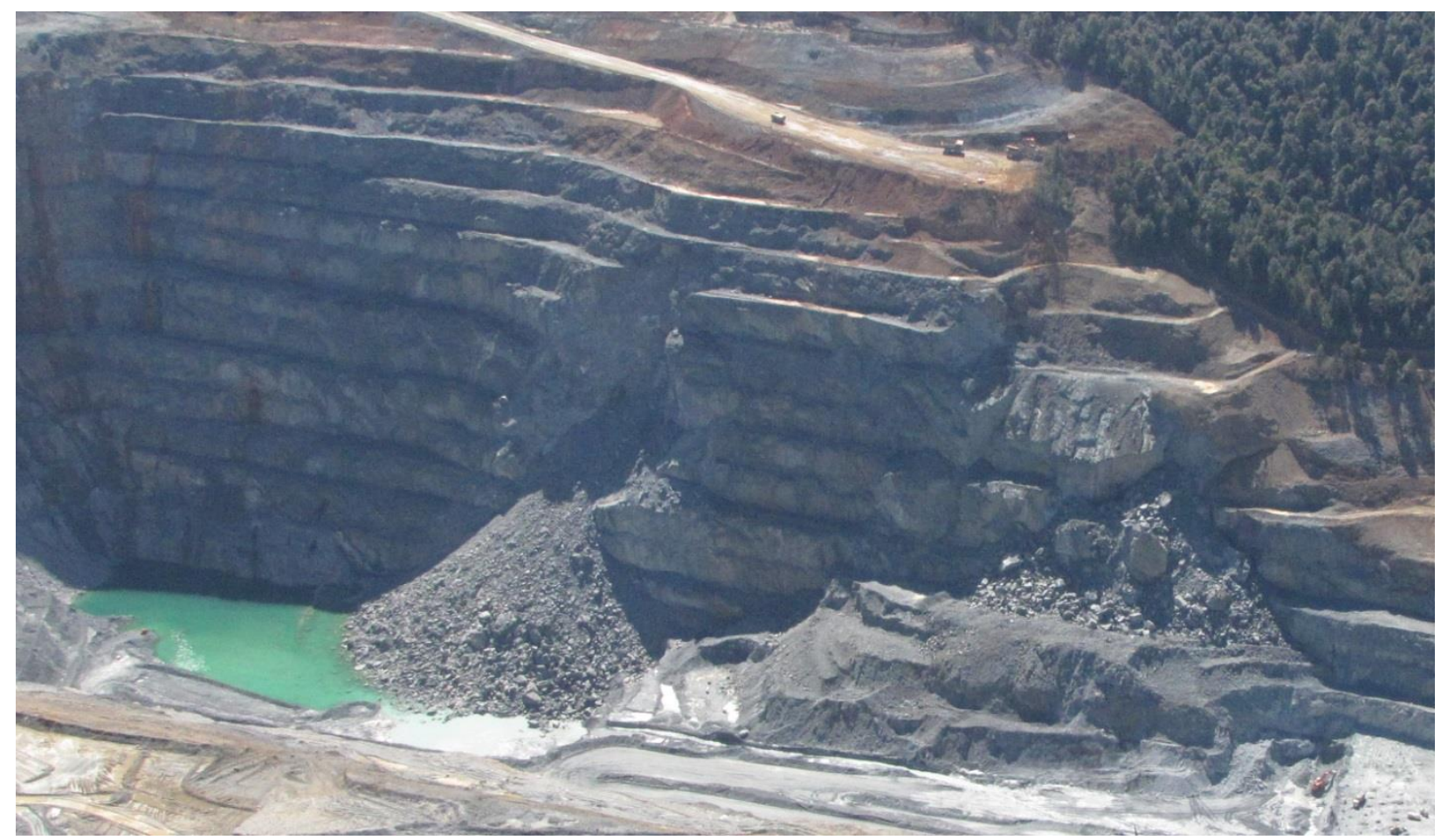

\section{Figure 417 June (left) and 30 August 2010 failures}

\section{$2 \quad$ Mine planning}

These two failures temporarily delayed access to a significant portion of the next two years of planned ore supply. Alternative plans were quickly put in place to bring forth other planned ore supplies and to develop two unplanned areas of reserves. With these strategies in place, a plan was developed to regain access to the ore.

The east wall recovery plan was developed over a three month period. Initially the focus was on cutting the wall well behind the slips and repeating the previous design slope. The main concern was with the working bench width and equipment selection. The mine had two fleets of Cat 785 and 789 haul trucks and a wide selection of excavators and shovels. Three Cat 777 haul trucks were also potentially available but these were utilised with feeding ore to the crusher. Drilling capacity included two Tamrock Titon 600 drill rigs (with remote drilling capability) and three Sandvik D45KS drill rigs.

As designs and schedule options were evaluated it soon became apparent that utilising the smaller fleet in a narrow cutback (such as shown in the left side of Figure 5), although moving less material, would not allow an acceptable vertical rate of advance. The mine planning group then began looking at alternative designs to reduce the pre-split drilling and rock support requirements; which typically take up a significant amount of time in the bench turnover cycle. Needing to move large volumes of material quickly presented options to look at cast blasting, whereby large volumes of rock above the slips and on the steep outer slopes could be thrown off the face and into the base of the pit. From that location a more much efficient loading and trucking operation could then take place.

Closer examinations of the two failures lead to potential options of utilising the fact that the failure had moved cleanly down and away from the haematite coated shear surface forming a prominent back scarp. Grange Resources had previously used drape mesh to stabilise a 1,500 $\mathrm{m}^{2}$ face, where a 7,000 tonne block of rock had been fired off the top of a $160 \mathrm{~m}$ high face. This was in a location where explosives had to be lowered by ropes and manually placed into large cracks to carrying out the blasting. Not being able to get machinery in to carry out scaling, lead to the decision to blast the rock and then drop drape mesh over the resulting face. That mesh was installed by drilling small anchor holes behind the main crack and attaching rolls of mesh lowered by helicopter. Following the blast, the mesh was unrolled down the face and 
manually laced together off ropes. With this experience, drape meshing options were also considered for the east wall recovery work (such as shown in the right side of Figure 5).

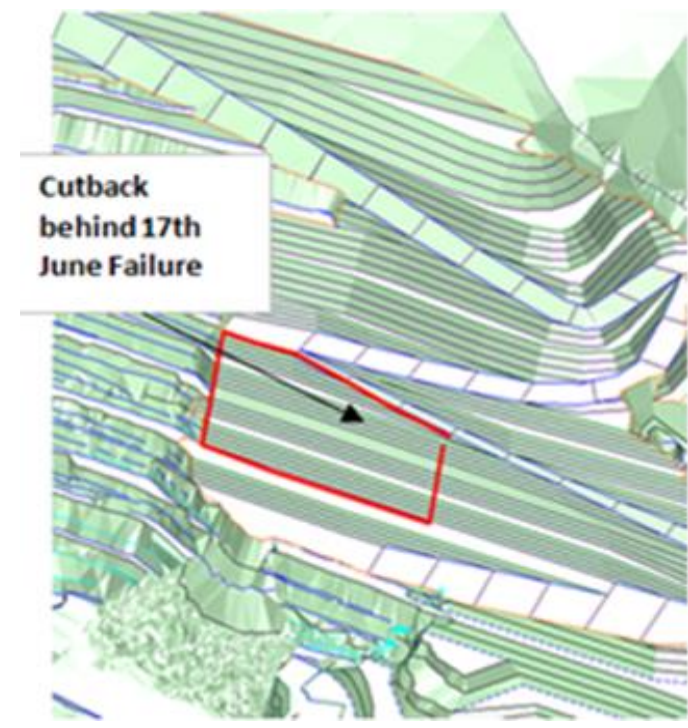

(a)

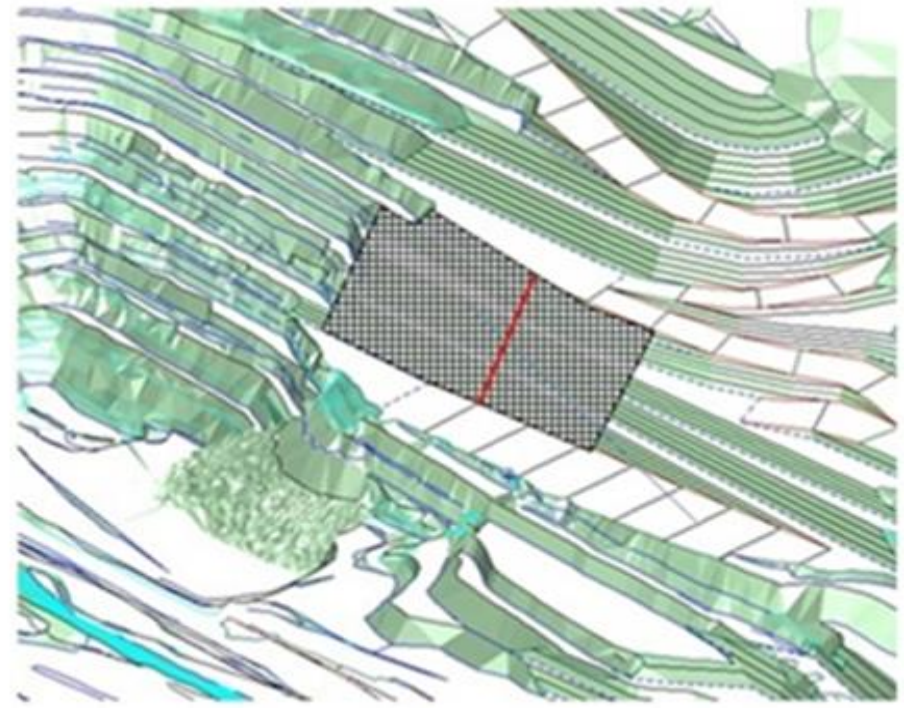

(b)

Figure 5 Examples of design options; (a) cutback design; (b) drape mesh design

After assessing over forty five design combinations, the following plan was adopted (refer to the schematic in Figure 6 and the cross-section in Figure 7):

- Remove the majority of the waste materials above the top of the backscarp at RL 260 ( $\mathrm{RL}$ - reduced level in metres) by a conventional Cat 789 truck and Hitachi 3600 shovel operation, hauling out to waste dumps to the north.

- Establish light vehicle and tracked equipment access from the southern end of the pit up to the $\mathrm{RL} 240$ level. This was to be carried out using a small fleet of $30 \mathrm{t}$ excavators and articulated trucks.

- Large haul truck access was in existence below RL 160 . Once tracked access was in place to RL 240 the fleet, supplemented by larger equipment when available, was to extend the southern large haul truck access up to RL 220.

These first two steps created the access from which the main remedial works were to be undertaken:

- Create a working bench at RL 260; from which a $40 \mathrm{~m}$ high cast blast would be used to throw as much material as possible, from in front of the haematite shear, down into the pit.

- Use remote controlled dozers working off the southern access road to create a bench at approximately RL 250 on the blasted material, from where a Hitachi 1200 excavator could carry out scaling of the backscarp.

- Progressively bulldoze and side cast waste material off the bench into the pit bottom (for later removal) and scale down to RL 220. With access from below established to RL 220 some of the southern end of the blast would be conventionally hauled to the south if enough working width existed.

- Install drape mesh, anchored off the RL 260 bench, to cover the exposed haematite shear; the primary purpose of this was to protect personnel and equipment working on the smaller RL 220 bench, during drilling and loading of the second cast blast. 


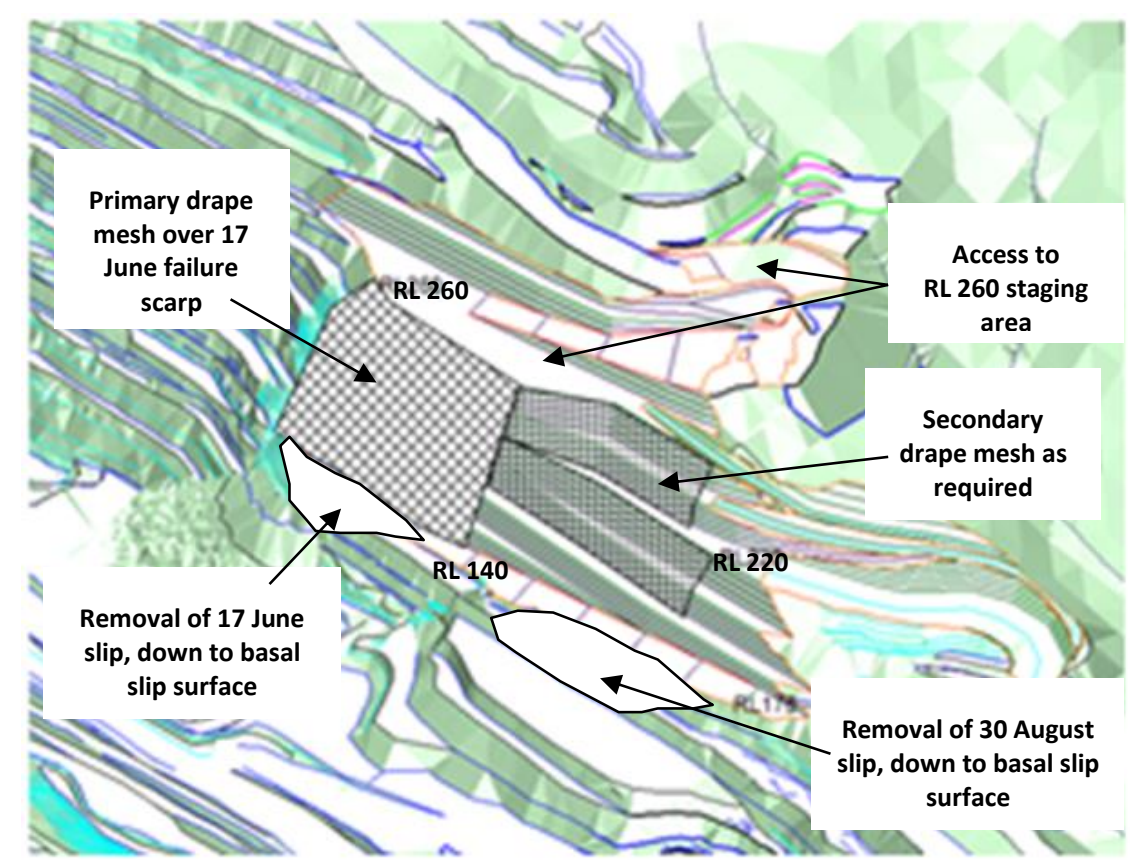

Figure 6 East wall recovery design with drape mesh components

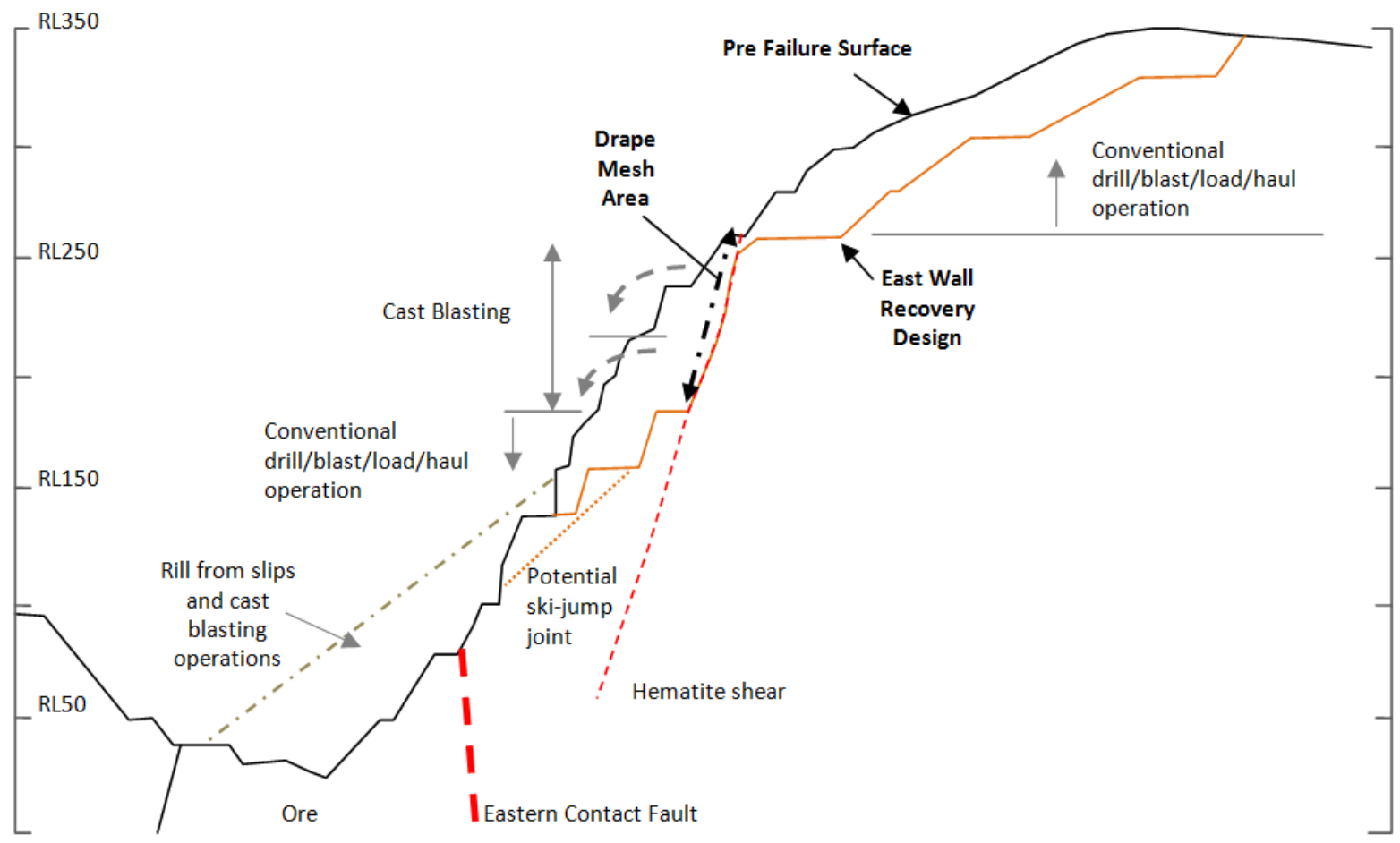

Figure 7 East wall recovery cross section

- Carry out a second cast blast from RL 220 down to RL 180.

- Repeat the excavation/scaling/meshing sequence with the option to conventionally haul waste material out on the southern access road subject to sufficient working width.

- From RL 180 excavation would revert to a conventional drill/blast/load/haul operation taking waste out from the southern large truck access road. 
- At around the RL 160 level it was expected to encounter the basal ski-jump joint on which the August failure slid on. At this point the disturbed slip material would simply be excavated down until meeting the original design.

- Removal of the rock slip and cast blast material would be carried out from ramps established off the west wall and pit floor areas.

Several design changes were made as the work progressed to adapt to conditions encountered, but essentially the plan was followed and completed. The main part of the plan that could not be followed was the initial intent to begin removing the rill material earlier by excavation from near the pit bottom. Due to the size of material in the rill, this proved to be too dangerous; unlike previous work on the northern slips. This necessitated its removal by drilling and blasting the larger blocks from above and ramping up onto the rill to reduce the excavation heights to manageable levels (12-15 m).

\section{Drape mesh design and selection process}

Drape mesh systems were required to provide protection to men and equipment working on relatively narrower benches against rockfall. Drape mesh systems act as an engineered risk control by controlling and containing falling blocks within the mesh envelope, and guiding them to the bottom of a slope. As falling blocks impact the mesh, these systems must be able to withstand mechanical damage caused by these impacts, and must also be able to transfer the forces resulting from the impacts in the mesh back into anchors that are installed at the top of the slope. The larger the maximum block size expected (design block), the greater these forces become, and hence a stronger mesh and system is required.

At Savage River different design blocks were identified across various areas, ranging from 0.3 up to $2 \mathrm{~m}^{3}$ ( 0.8 to $5.4 \mathrm{t}$ ) requiring the potential for different drape systems to be installed. Tenders were called to supply mesh systems to deal with the design block sizes. To conform to Grange Resources quality assurance requirements, the prospective suppliers were required to provide design calculations and evidence of system(s) testing, if available.

A three drape Geobrugg ${ }^{\mathrm{TM}}$ system was selected. The three systems comprised:

- SPIDER ${ }^{\circledR}$ S4-130 mesh (for crest support of highly broken rock with the largest block size).

- $\mathrm{TECCO}^{\circledR} \mathrm{G} 80 / 4$ mesh (for general protection over the main back scarp area).

- DELTAX ${ }^{\circledR} \mathrm{G} 80 / 2$ mesh (a light weight mesh for smaller blocks on blasted slope batters).

Note: the 130 and 80 designations refer to the effective diameter in millimetres of the rhomboid mesh; the 4 and 2 refer to the wire diameter in millimetres.

The systems all utilised single twist high tensile wire mesh, with a tensile strength of $1,770 \mathrm{~N} / \mathrm{mm}^{2}$, which is four times higher than mild steel. The advantage of utilising a single twist high tensile wire mesh is the uniformity of the mesh behaviour; the strength of the mesh is the same regardless of where it is loaded, eliminating any weak link in the system. This is critical when dealing with rockfall, as falling blocks can puncture the drape mesh. To confirm the suitability of the mesh type required, the design for each drape system was based on 1:1 field tests, which verified the load capacity of each mesh.

To speed up delivery times, a fourth mesh type $\mathrm{TECCO}^{\circledR} \mathrm{G} 65 / 3$ mesh was also supplied as a partial substitute for the original $\mathrm{TECCO}^{\circledR} \mathrm{G} 80$ mesh. A further tender appointed an external contractor to undertake the installation and this was supplemented with a day works crew (to support the rope specialists) and cranes to assist in mesh installation and emergency egress support provided by Grange Resources (Tasmania) Pty Ltd.

\section{$4 \quad$ Cast blasting}

Progress of the upper access down to the RL 260 staging area (shown in the top of Figure 4) was undertaken whilst the tendering processes were completed. Upon reaching the RL 260 level, anchor and 
mesh supplies had arrived and installation of the anchor system was undertaken on the northern side, behind the main scarp of the 17 June failure. In the central and southern ends, the first of the two $40 \mathrm{~m}$ high cast blasts was drilled and fired (Figure 8).

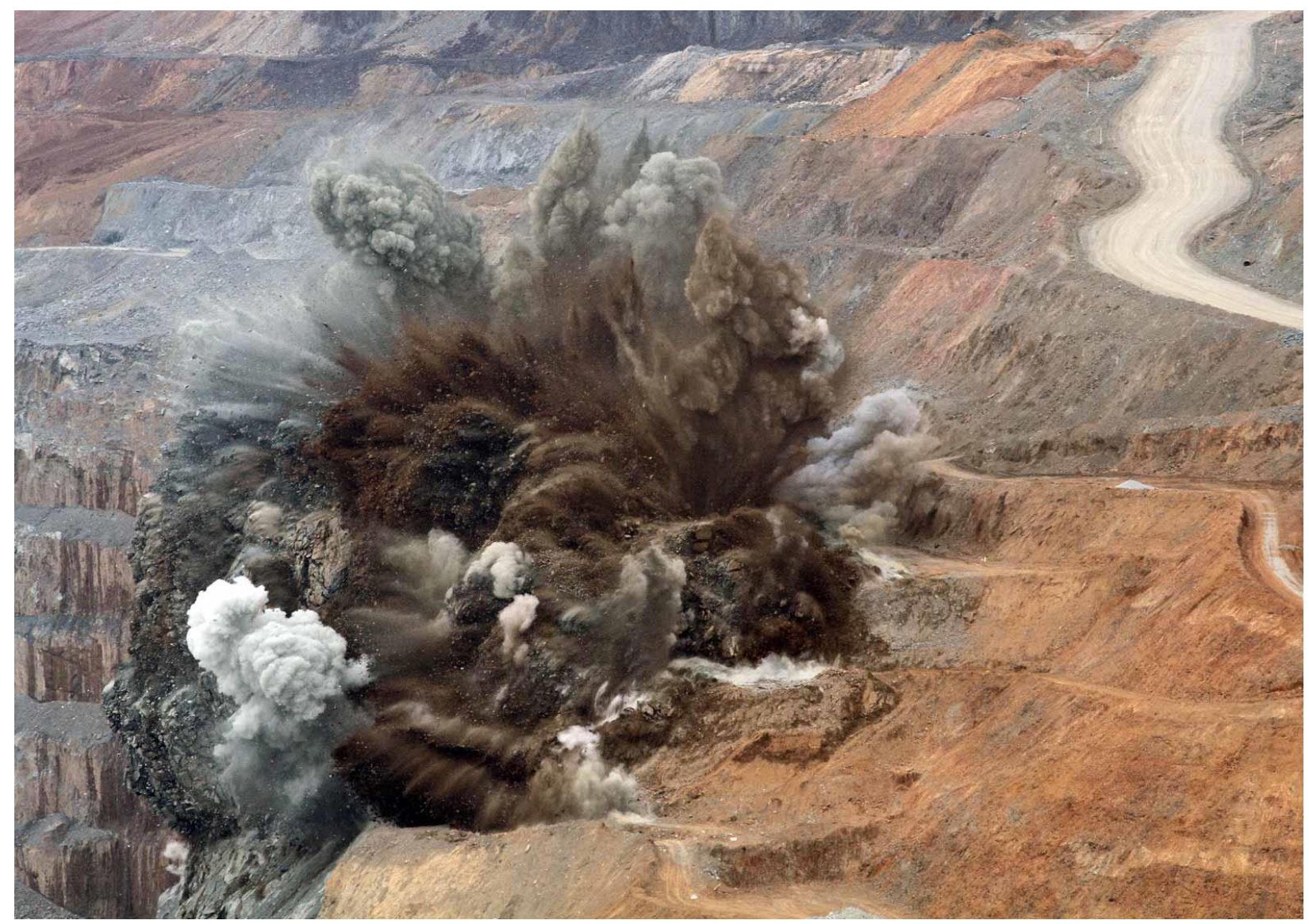

Figure 8 RL 260-220 cast blast

Both cast blast volumes were approximately $1.2 \mathrm{Mt}$; of which between $30-35 \%$ of the material was displaced over the pit edge and onto the pit floor or onto the slide material rill areas.

The key features of the cast blasts were:

- Dipping face angles requiring carefully measured face burdens, being optimised on a hole by hole basis from face scans.

- Targeted drilling through cracks and voids.

- An $8 \mathrm{~m}$ wide berm half way down the blast face requiring a smaller trim blasting component within the design with angled batter holes.

- Drilling of some areas of the blast pattern with the use of Tamrock Titon tele-remote drill rigs.

- Collar pipe placed in each blast hole to prevent hole collapse issues.

- The use of an Ikon RX electronic detonation system with the ability to know if any detonator leads were damaged during loading and thus enabling reprime of the blast hole with additional primers if needed.

- Each $40 \mathrm{~m}$ blast hole was double primed (one primer at subgrade and one primer 2 to $3 \mathrm{~m}$ below the stemming to ensure detonation of the complete column). 
- The use of Aquamax1670 16 Bulk Emulsion (a $1.2 \mathrm{~g} / \mathrm{cc}$ density 70/30 single salt emulsion/ANFO bulk explosive product), produced By Downer Blasting Services (required due to $90 \%$ of blast holes containing water).

- Use of a 70/30 blend provides a viscosity well suited to loading angled holes, with its ability to run and flow into position when required, as opposed to choking or blocking up in the hole during loading, causing bridging which higher Ammonium Nitrate content bulk explosives are more likely to do.

- Utilisation of the capability of Savage River's Merlo ${ }^{\mathrm{TM}}$ remote explosives loading machine (long reach teli-handler with engineered attachments), to load blast holes.

The first blast was considered to have displaced more volume than the second blast but difficulties had been encountered in drilling through the open cracks extending southwards from the 17 June slip. Following the blasting, a portion of the northern end, which was in front of the open cracks, was not fully blasted; leaving a large pinnacle of rock, refer to Figure 9 (taken after excavation of the majority of the blasted material). This area required considerable additional remote dozer, excavator and secondary blasting work to eventually achieve the RL 220 floor. As shown in the photo a considerable amount of material below the blast floor was also displaced.

The additional time needed to remove the pinnacle resulted in the southern half of the second cast blast being 'slept' for four weeks; with no detrimental effects.

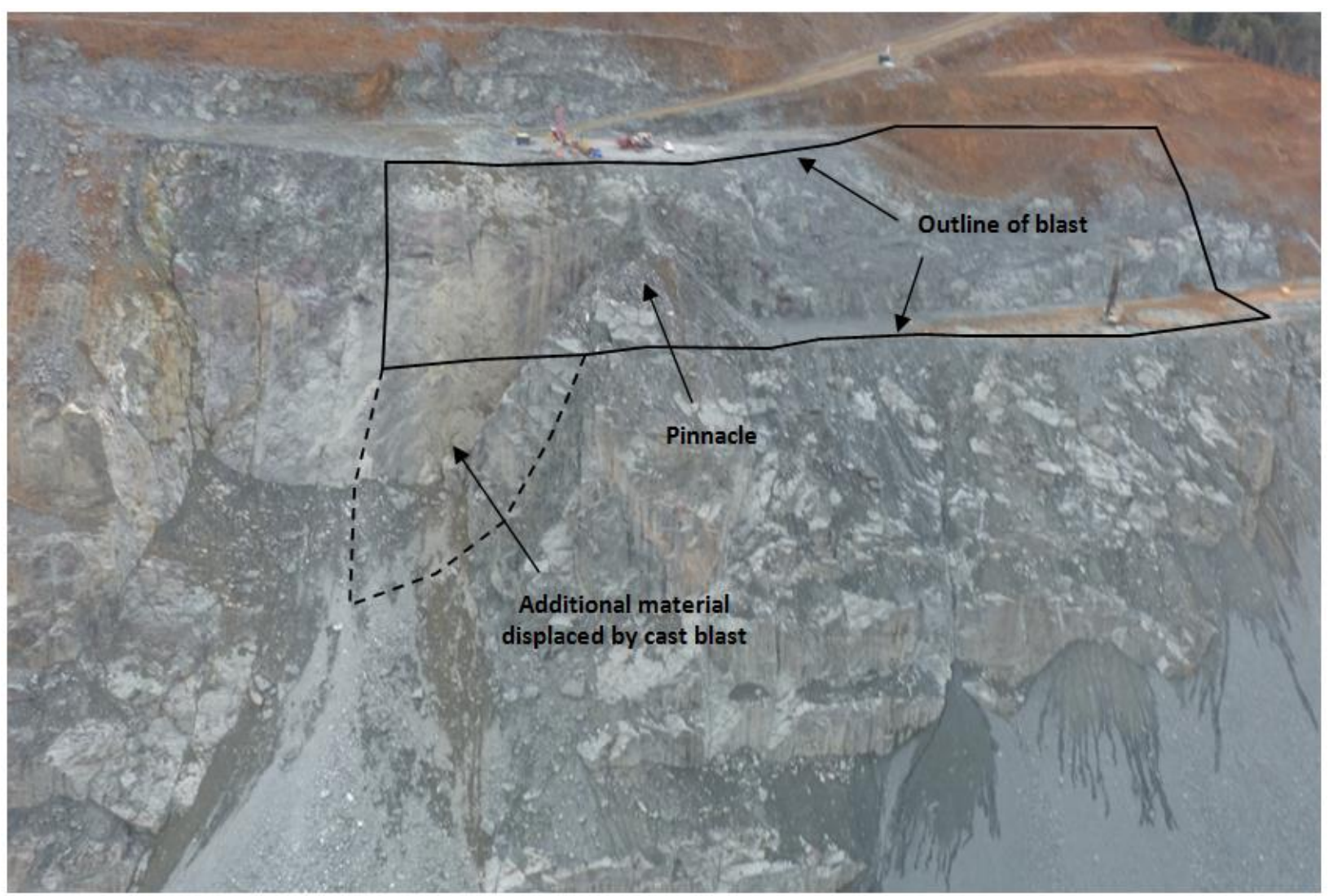

Figure 9 Effect of first cast blast 


\section{Drape mesh installation}

The drape mesh installation was preceded by the installation of the anchor system, set approximately $10 \mathrm{~m}$ behind the RL 260 crest. The anchors for the SPIDER ${ }^{\circledR}$ and TECCO ${ }^{\circledR}$ mesh systems were $18.5 \mathrm{~mm}$ diameter, $4 \mathrm{~m}$ long wire rope anchors; attached to $22 \mathrm{~mm}$ diameter wire top ropes (Figure 10). The light weight DELTAX ${ }^{\circledR}$ mesh was to be anchored off $10.5 \mathrm{~mm}$ diameter, $2 \mathrm{~m}$ long anchors; attached to $16 \mathrm{~mm}$ diameter wire top ropes.

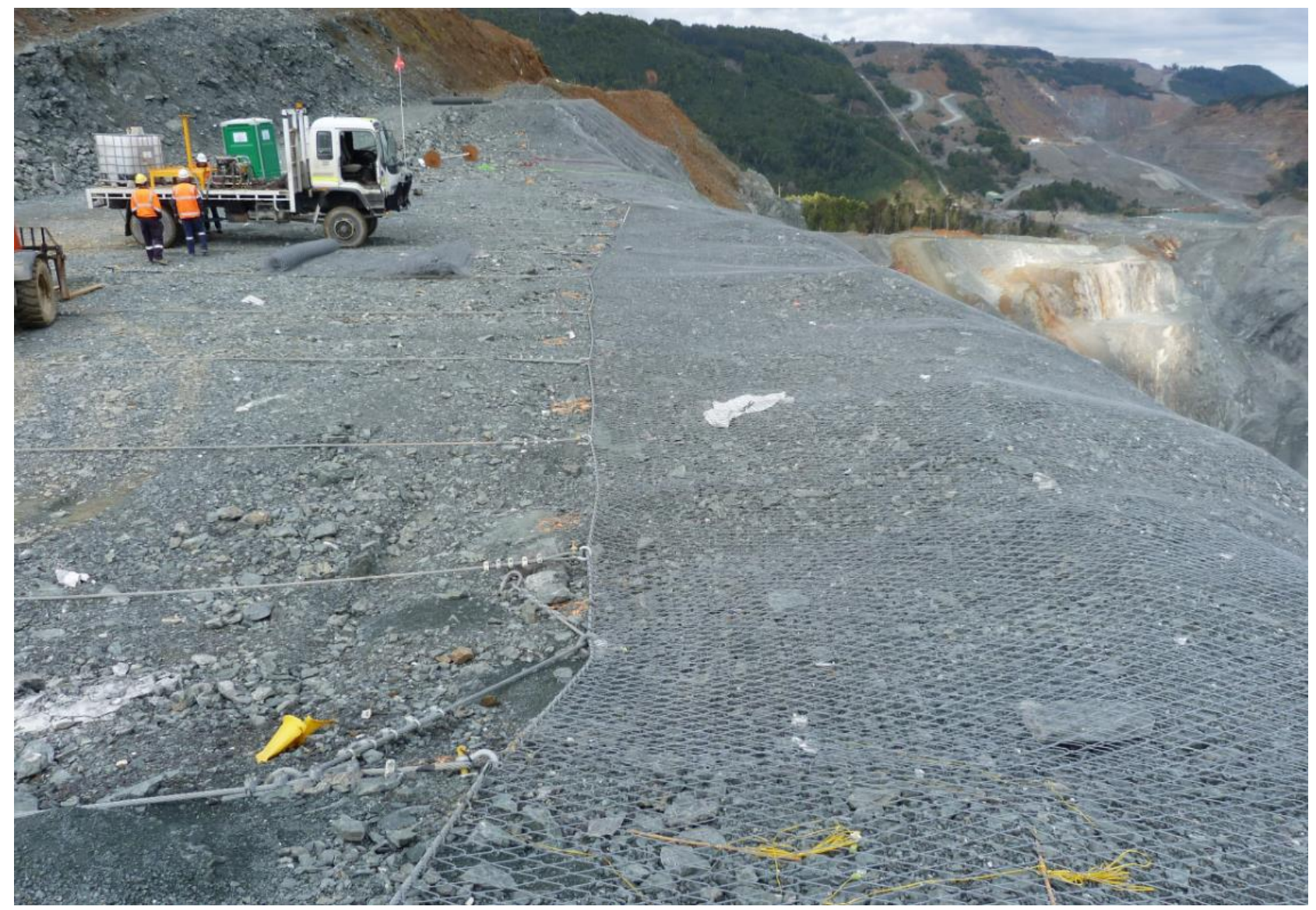

\section{Figure $10 \mathrm{TECCO}{ }^{\circledR} \mathrm{G} 80 / 4$ mesh anchor system layout and crest mesh}

At the northern end of the cutback, behind the 17 June slip, the crest rock loosened significantly after the first cast blast, requiring three additional crest trim shots to remove large blocks. In one case the initial mesh had to be removed and later reinstalled. The trim shots required a new set of anchors to be installed over a short section. Although the majority of the loose rock was blasted or scaled away, the SPIDER ${ }^{\circledR}$ S4 mesh was concentrated in a specific area to retain larger blocks along the crest (Figure 11).

The selection and placement of the various mesh types was decided on after the initial cast blasting and scaling results were observed. In general, the cast blasting was very successful in exposing a relatively smooth haematite shear surface that contained a few overhang areas. The final distribution of the various mesh types can be seen in Figure 12.

The TECCO ${ }^{\circledR}$ and DELTAX $^{\oplus}$ mesh arrived in 30 and $60 \mathrm{~m}$ long, by $3.5 \mathrm{~m}$ wide rolls; although some of the initial TECCO ${ }^{\circledR} \mathrm{G} 65 / 3$ was $40 \mathrm{~m}$ in length. The SPIDER ${ }^{\circledR} \mathrm{S} 4$ mesh came in $25 \mathrm{~m}$ long by $5 \mathrm{~m}$ wide rolls. The selection of the mesh layout was based around attempting to install an initial $60 \mathrm{~m}$ high drape, from which a further 30 or $60 \mathrm{~m}$ of mesh could be hung. Having the $40 \mathrm{~m}$ long rolls of TECCO ${ }^{\circledR}$ mesh allowed for covering of protruding rock block areas while keeping the base of the first drape relatively consistent. 


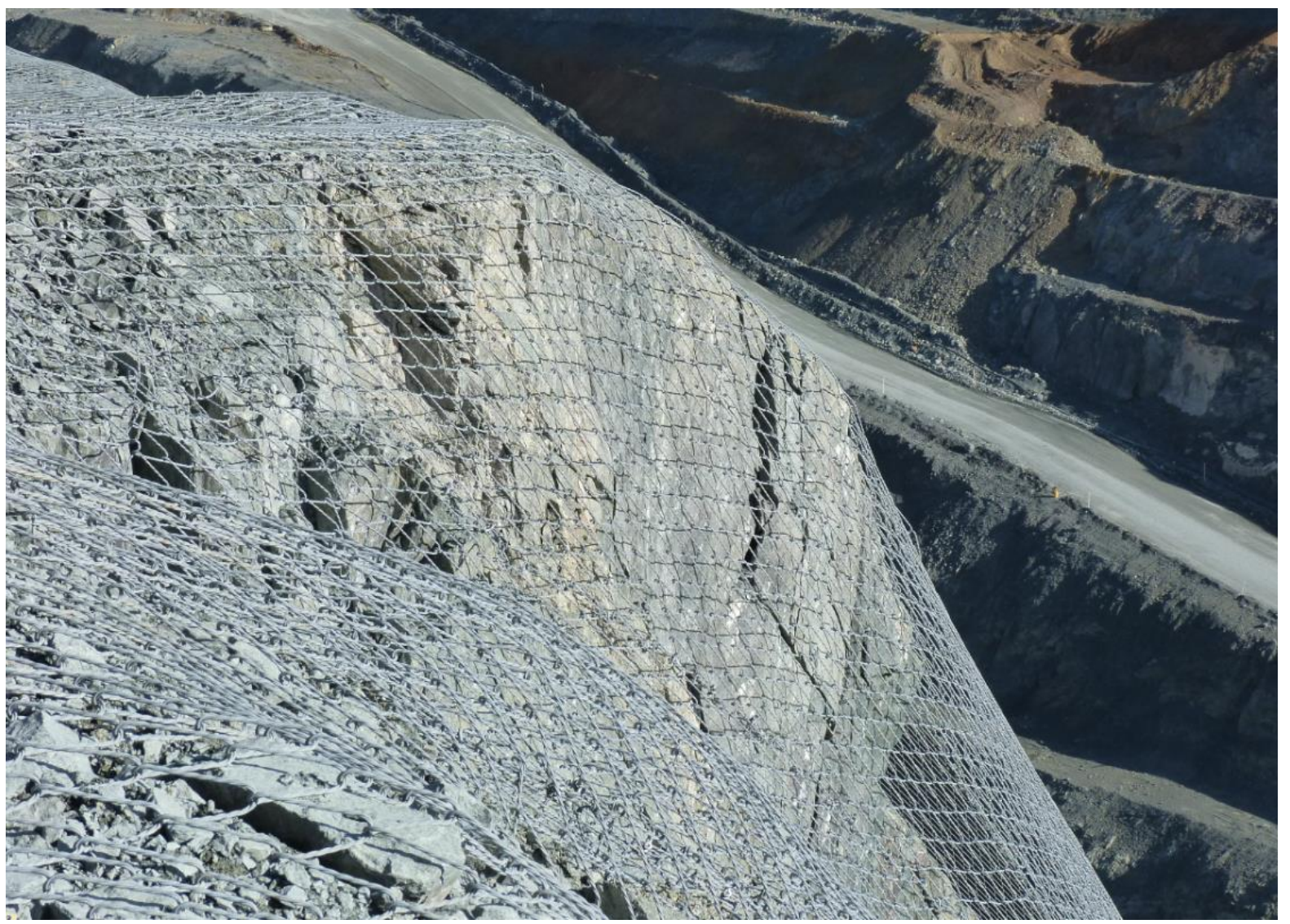

Figure $11 \mathrm{SPIDER}^{\circledR} \mathrm{S}_{4-130}$ mesh

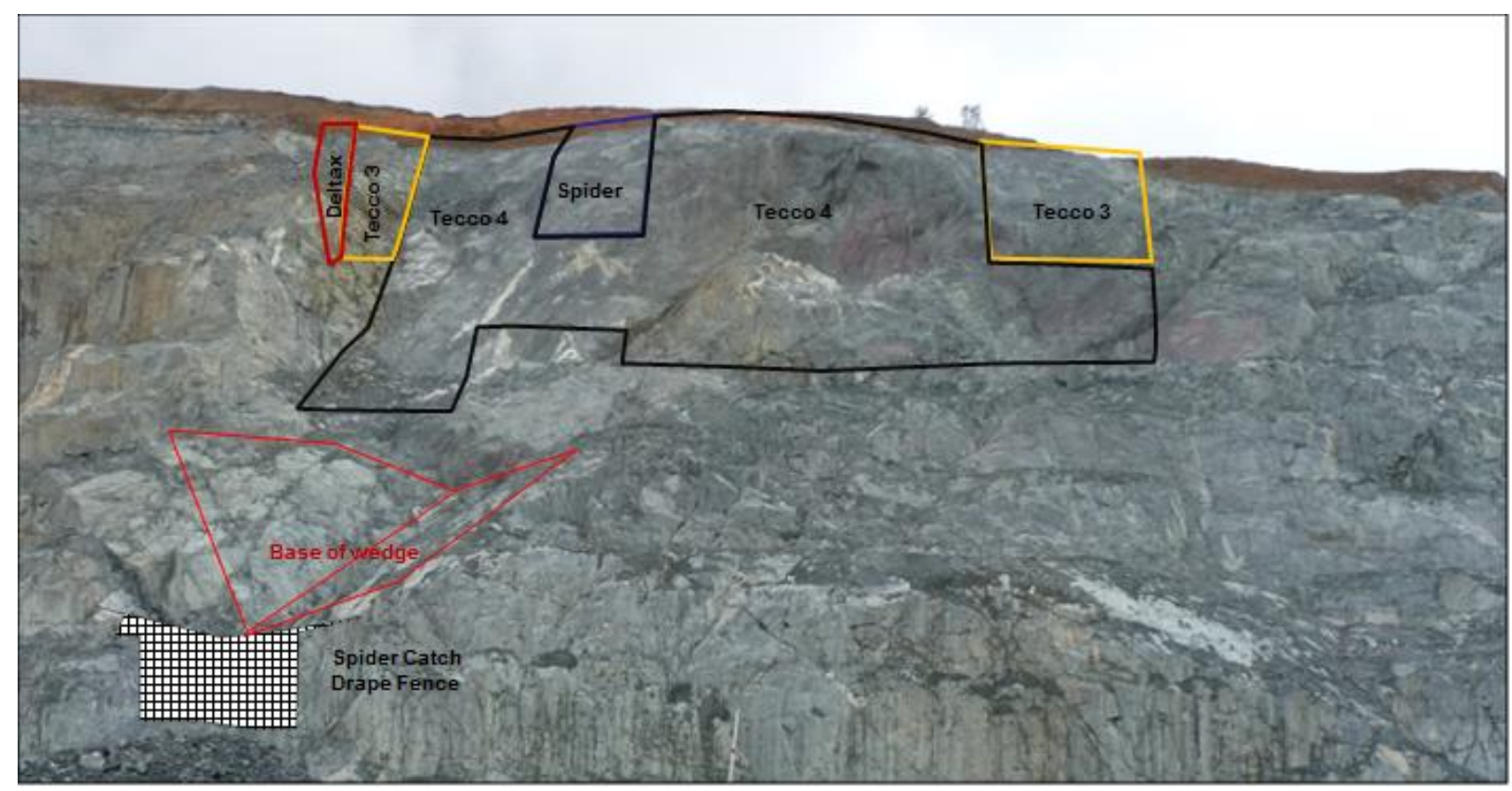

Figure 12 Final excavation and drape mesh coverage areas

The initial upper drape mesh installation was carried out by anchoring and overlapping the rolls of mesh to the top rope. The rolls were then pushed off the crest and manoeuvred in place by the rope specialists and then laced together. A 50 tonne extendable boom crane was then used to lower the next roll of mesh to the base of the upper drape where they were shackled together. These second sets of rolls were then unclipped to allow the mesh to unravel further down the slope. In most cases the mesh was extended to 
$90 \mathrm{~m}$ in height. One area reached $120 \mathrm{~m}$ in height but that required the mobilisation of a 150 tonne extendable boom crane to provide sufficient reach (Figure 13). Although the cranes were not in the original plan and budget, they significantly sped up the mesh placement work.

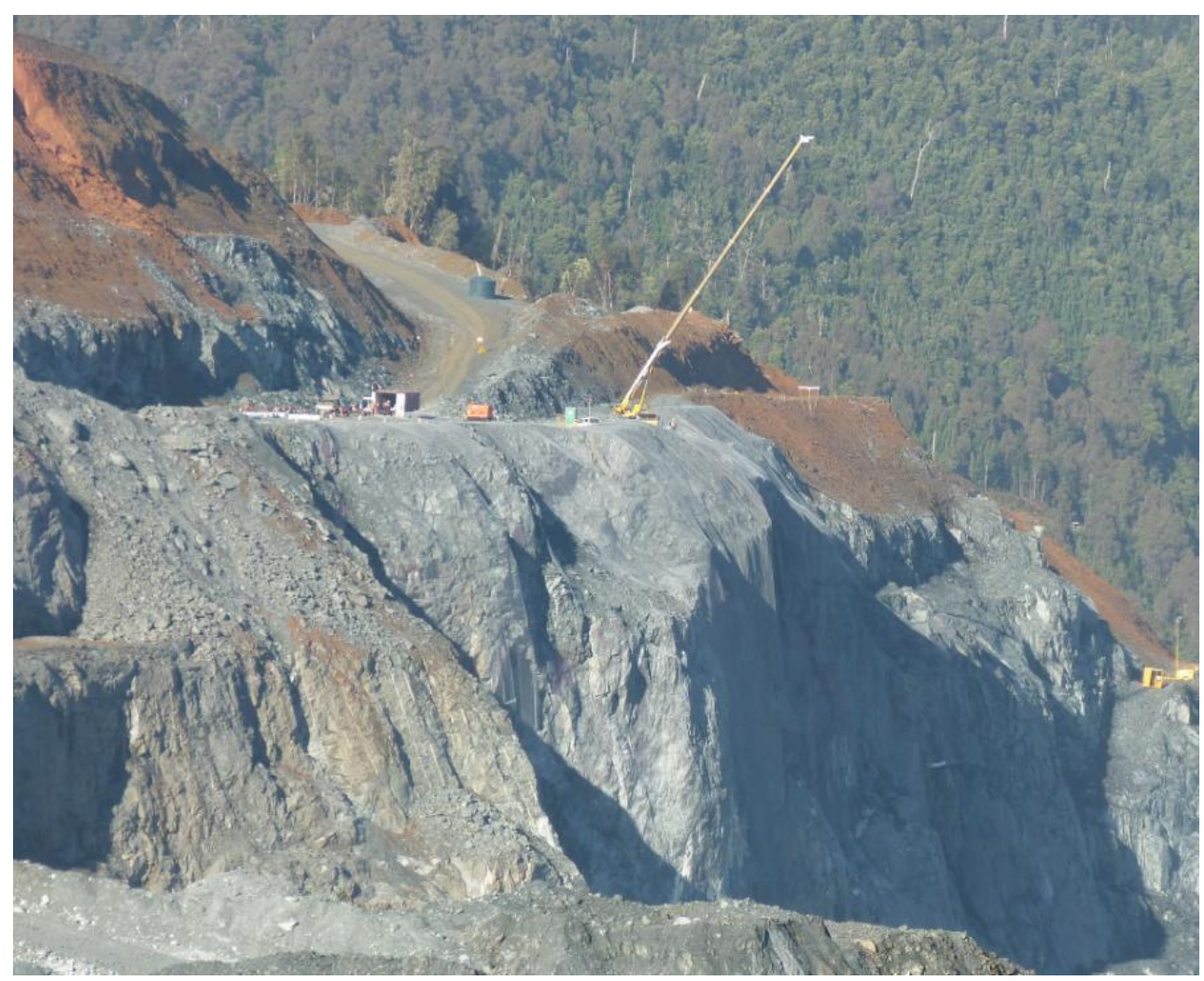

Figure 13 Mesh installation with 150 tonne crane

By far the most time consuming task was the clipping and then weaving together of the edges of the mesh; utilising $6 \mathrm{~mm}$ diameter wire rope. As it could take 20-30 minutes to climb back up the ropes, the crane provided rapid access for the rope specialists.

The excavation and meshing activities overlapped very well. In the six month installation program, there were very few times when either activity held up the other. During that time, a total of 15,355 $\mathrm{m}^{2}$ of mesh was installed, at an average cost of AUD 110 per $\mathrm{m}^{2}$. This was within $10 \%$ of the budgeted unit rate. Very little of the light weight DELTAX ${ }^{\circledR}$ mesh was installed, so this costing is indicative of the heavier meshes.

\section{Drape mesh performance}

The drape mesh performed exceptionally well and allowed the main excavation activities to be carried out under safe conditions right through the high winter rainfall period. The extremes of encountered rock conditions can be seen in Figures 14 and 15.

The highly fractured rock mass, evident in Figure 15, is located to the north of the SPIDER ${ }^{\circledR}$ mesh. There were concerns that blocks of rock dropping down the drape mesh could exit the mesh and shoot out from the base of the wedge of the 17 June failure (Figure 12). To arrest rocks within the drape, extra mesh (the extension to $120 \mathrm{~m}$ ) was placed on the underlying ski-jump joint. In addition an open based catch fence of SPIDER ${ }^{\circledR}$ mesh was placed at the base of the failure; to slow down any cascading rocks and drop them directly down into the pit bottom. 

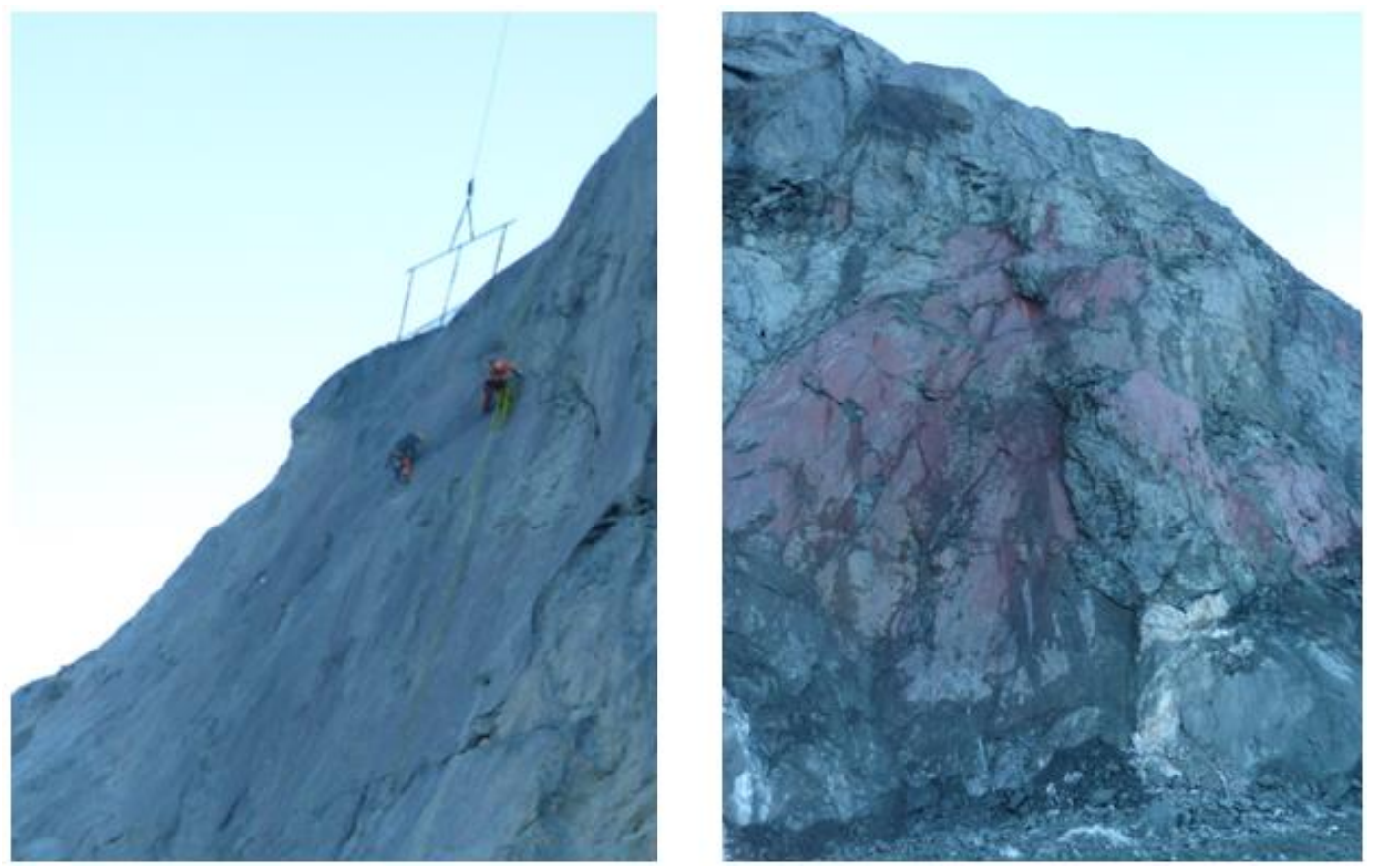

Figure 14 Smooth and blocky/overhanging shear surfaces

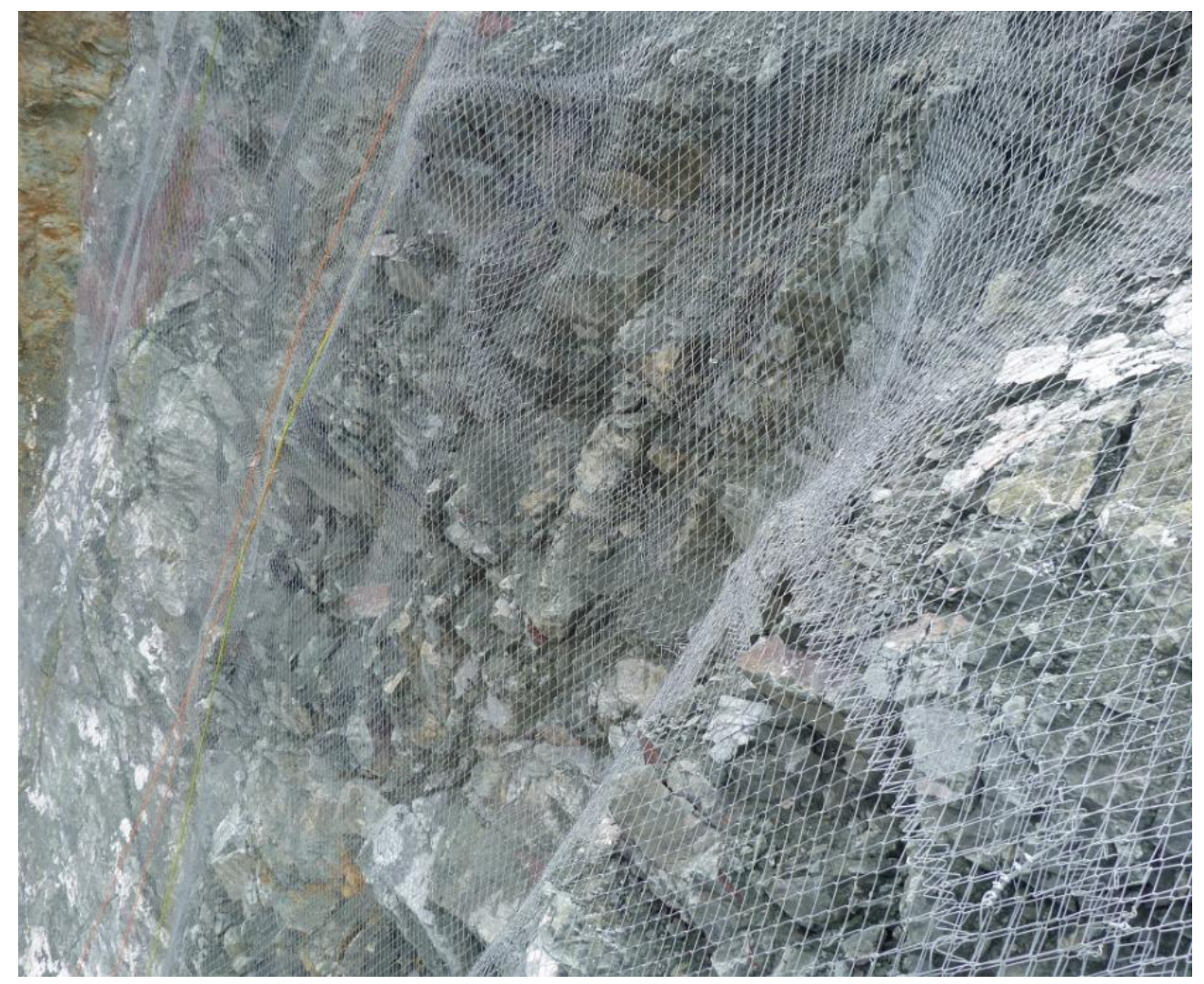

\section{Figure 15 Highly fractured rock mass stabilised by $\mathrm{TECCO}{ }^{\circledR} \mathrm{G} 80 / 4$ mesh}

The drape mesh system was started in April 2011 and completed in early October 2011 and, despite having another recent large failure below the base of the drape mesh, no rocks are known to have emerged from the base of the drape. Several rockfalls were heard and a few rocks were noted at the base of the drape but it was difficult to identify where they came from. In most cases they seem most likely to have dropped out of overhang areas on the haematite shear surface. 
When drape mesh systems are designed, it is mainly the ability to withstand impacts from falling rocks that is considered. In the Savage River case it is apparent that the mesh also provided considerable 'interface friction' or 'confinement', which prevented the large blocks of rock at the crest (Figure 11) or the highly fractured rock mass (Figure 15), from being displaced. It appears the drape mesh suppliers are reluctant to consider this component of additional stability that drape meshes may be able to provide; possibly due to the highly variable situations and the difficulties in providing standard designs to suit those conditions.

\section{$7 \quad$ Radar monitoring}

Grange Resources manage their pit stability issue with the aid of Reutech Monitoring and Surveying Radar (MSR300s) units (Macqueen et al., 2013). In the Savage River experience such radars have consistently picked up rockfalls of greater than $250 \mathrm{t}$ of material; but no rockfalls of this size have been recorded to date in the meshed areas. The majority of the rocks noted at the base of the drape mesh were likely from much smaller episodes and therefore, the radars were not capable of consistently detecting or monitoring them. Radar monitoring of the meshed areas has picked up scattered movements in overhang areas; but this is related to movement of the mesh due to wind conditions.

Of interest was the large area of highly fractured rock (Figure 15) that one would assume to have undergone some movement. No definitive movements were recorded there. As radar monitoring is disrupted and difficult to interpret when installation activities are underway, the high fractured area may well have moved during the installation period, but was quickly stabilised by the drape mesh.

In summary our radar monitoring experiences with drape mesh have shown that where the mesh is allowed to move even slightly, the radar detects this movement. This should allow detection of rock movement where the mesh is tight against the rock; but may obscure any real wall movement in overhung areas of the wall.

\section{Conclusions}

The installation of the drape mesh and the use of cast blasting were instrumental in allowing Grange Resources to meet their proposed mining schedule and ore recovery targets. The cost of the drape mesh was met within the overall budget (due to less mesh needing to be installed) and at about $10 \%$ more than the budgeted unit rate per square metre.

The drape mesh prevented potential rockfalls that could have occurred in the variable rock mass conditions from disrupting operational activities occurring below the progressively installed drape mesh. Occasional small scale rockfalls may have occurred behind the mesh, but no major rock movements were observed to have breached the drape.

\section{References}

Macqueen, G.K., Salas, E.I. and Hutchison, B.J. (2013) Application of radar monitoring at the Savage River Mine, Tasmania, in Proceedings International Symposium on Slope Stability in Open Pit Mining and Civil Engineering (Slope Stability 2013), P.M. Dight (ed), 25-27 September 2013, Brisbane, Australia, Australian Centre for Geomechanics, Perth, pp. 1011-1020. 